\title{
Marriage Therapy for Ecologists and Landscape Architects
}

Steven N. Handel

Hello. Come in. What's on your mind; why have you come to chat with me?

\section{"We have such different backgrounds."}

Ecologists interest start with an exploration of the natural world, its structure and function. Architects and landscape architects start with human needs and how constructed features can answer those needs. Of course you have these different backgrounds, and your training is so different. At most universities even your training is even in different colleges; so of course there are tensions. But think of what you have in common! You share interests in beauty, quantitative analysis, long-lasting projects, and service to your communities. These are not things to sneeze at, or walk away from.

\section{"I hate it when he ignores me."}

You're both so busy with too much work and not enough help to reach your goals. You're used to the cultures of your own professions and the traditional partners with whom you work. Reaching out to a different specialty and to people who use different idioms and work in different locations and even dress differently, it's no surprise that you feel ignored by each other. All new relationships take time and nurturing to get to know each other. You shouldn't give up on a relationship when it's just getting started.

\section{"She never calls."}

Sometimes when we're involved in our own professional activities, we neglect to see the moments when another person's additions or constructive critiques could be of use to us. When we're advancing our daily chores, it's hard to stop and say, "I wonder what she would think of this. I wonder if a new perspective from another profession could add something unusual and valuable here." Often a lack of communication is just a naïve ignorance of how diverse perspectives can add value. Perhaps inaction is not malicious, but it's just a corollary of not knowing where useful help can be found. This can be overcome.

Ecological Restoration Vol. 32, No. 4, 2014

ISSN 1522-4740 E-ISSN 1543-4079

C2014 by the Board of Regents of the University of Wisconsin System.
"He always wants it his way."

When people have lived and worked alone (or in a cubicle, maybe?) for a long time or just worked with people that have similar points of view, they want the internal reward of feeling that they know how to do the project right. Collaborating with someone from a different background is at best challenging and at worst may even seem insulting. Do you sometimes think, "I've been doing it one way for so long, now he thinks I'm not doing it right? I've been trained one way, my projects have always been approved, and now he thinks my designs won't work right or are even shabby? Why did I ever ask him for comments?"

It is sometimes hard to take two very different perspectives and mesh them into a greater whole. This is not a battle that one person must win. But think of this professional union as a new creative approach to master. Even in ecology, two very different organisms can work together for an advantage to them both, a mutualism. The organisms usually are quite distinct in their needs and abilities, their niches, but together a more promising and sustainable future is possible. Biotic mutualisms can be a simple model for professional linkages. Let's stick to the project at hand, not to an attitude that critiques are a personal attack.

\section{"She's so messy."}

$\mathrm{Oh}$, the modernist design idiom is so elegant, so geometric, so understated. Ecological structure is usually asymmetric, variable, and spatially unpredictable. It's the Odd Couple for creating the landscape. Sometimes irregular landscape ecological designs do seem messy, but "messiness" is a loaded word when we could say diverse or mosaic or idiosyncratic. In a changing world, sometimes complex biotic structures can yield stability, as certain elements fade away and die and others expand under the new conditions. Messy may be a word that's inappropriate as we advance landscape excellence, even if the habitats don't have repeating patterns or a uniform size distribution. Let's think outside the box. Maybe I should say outside the amoeboid shape.

\section{"He's done so much to hurt me."}

Ecologists have been distressed by long lists of built projects that ignore or weaken ecological structure and function, 
driving thick wedges of disrespect between design professionals and clients and the people who manage and study natural landscape systems. So often financial arguments trump the importance of restoring ecological systems whose real values (ecological services) are obscure to land owners and regulators and whose contribution to sustainable communities does not appear in annual municipal budgets. The ecological values are not translated from academic understanding to numbers in a civic ledger that can be used to argue against degradation of those services. The hurt is to the ecological worker's ego, the real needs of the community, and the long-term financial plans of a healthy government organization. The parallel hurt to the designer and client is when an ecologist advances a restoration agenda alone, smugly ignoring the values of a new design for other community goals that are seemingly distant from securing solely ecological services.
Improving this relationship is going to take some time. I can't promise a happy ending, of course, but ask you to remember three things: First, your goals for a sustainable, healthy landscape are parallel, not divergent. Keep that in mind when you seem to have momentary troubles communicating. Second, you are both driven to improve the landscape, not watch it continually degrade; remember you're soul mates, at least in that way. Third, we live in a rapidly changing world, climate, sea levels, movement of species, and mixing of biotic communities. These are all spinning fast towards a future that is hard to predict. Ecologists and designers are our only real protection against the troubles ahead. We need you to work together; don't let us down.

See you next week.

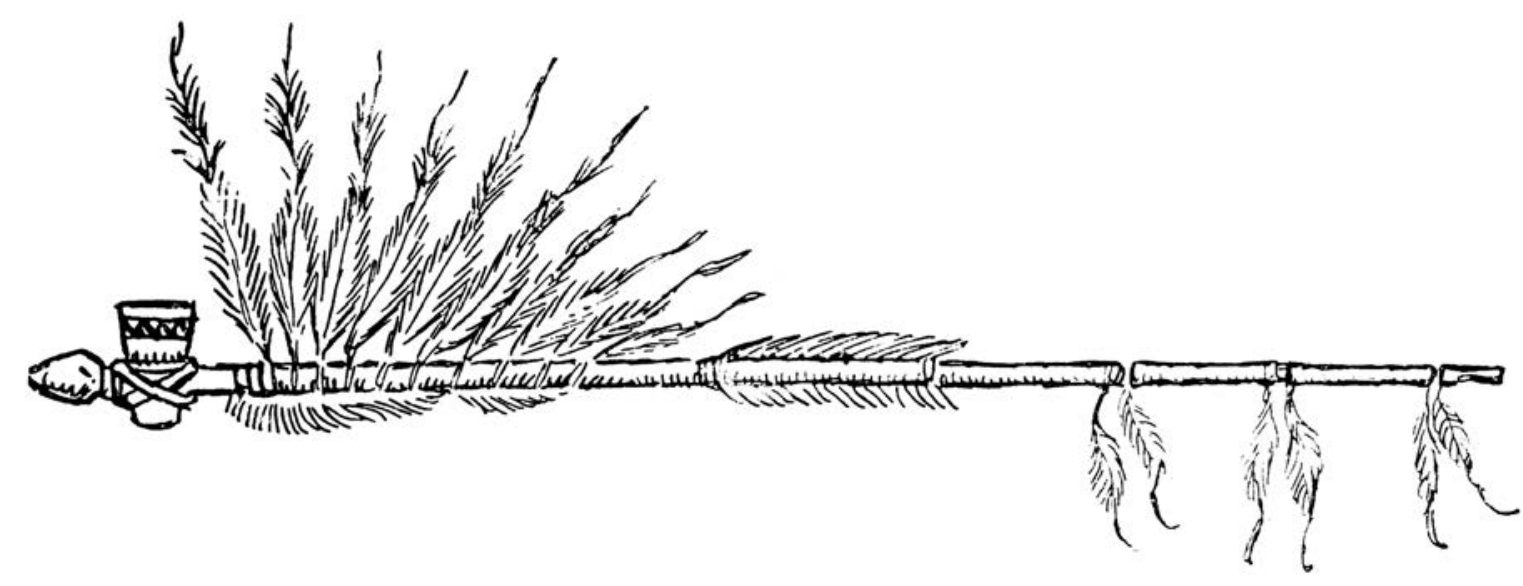

Ellis, E.E. 1899. Ellis's History of the United States. Minneapolis, MN: Wester Book Syndicate. The Florida Center for Instructional Technology, fcit.usf.edu. 